\title{
STUDY OF HAEMATOLOGICAL ABNORMALITIES IN HIV PATIENTS AND CORRELATION WITH BONE MARROW CHANGES AT A TERTIARY CARE CENTRE
}

\author{
Hemant R. Guptaํ, Balram Yadav², Utina Kichu³, Minal A. Meshram 4
}

${ }^{1}$ Associate Professor and Unit Head, Department of Medicine, Grant Government College, Mumbai, Maharashtra, India.

${ }^{2}$ Senior Resident, Department of Medicine, JJ Group of Hospitals, Grant Government College, Mumbai, Maharashtra, India.

$3 J u n i o r$ Resident, Department of Medicine, Grant Government College, Mumbai, Maharashtra, India.

${ }^{4} J u n i o r$ Resident, Department of Medicine, Grant Government College, Mumbai, Maharashtra, India.

ABSTRACT
BACKGROUND
HIV infection is a global pandemic with cases reported from virtually every country. In 2016 India had $80,000(62,000-10$
new HIV infections and $62,000(43,000-91,000)$ AIDS-related deaths. There were $2,100,000(1,700,000-2,600,000)$ peop
with HIV in 2016, among whom $49 \%(40 \%-61 \%)$ were accessing antiretroviral therapy.(1) India stands third in HIV epide
the world(2) with 2.1 million people living with the virus.(2) Epi disorders of haematopoietic system including anaemia, leuks
and/ or thrombocytopenia are common throughout the course of HIV infection. ${ }^{(3)}$
The objectives of the study are-
1. To review and describe bone marrow abnormalities and associated peripheral abnormalities in HIV/ AIDS patients.
2. To establish the prevalence of trilineage cytopenia.
3. To determine presence of secondary malignancies.

\section{MATERIALS AND METHODS}

A prospective descriptive clinical study with 104 HIV positive patients consisting of 39 AIDS and 65 non-AIDS patients were undertaken to study haematological abnormalities in HIV patients and correlation with bone marrow changes of tertiary care centre.

\section{CONCLUSION}

Peripheral and bone marrow abnormalities are common in HIV related disease and has got significant impact on clinical outcomes and quality of life.

- $\quad$ HIV is prevalent more in males as compared to females in sexually active age group of 20 - 49 yrs.

- Bone marrow was hypocellular, five times more common in AIDS than in non-AIDS.

- Dysplasia is common in AIDS more than non-AIDS.

\section{RESULTS}

Total no. of patients included in the study were 104, out of which 66 were males and 38 were females with sex ratio (M: F= 1.73: 1). These 104 patients were examined. Their clinical and haematological parameters were analysed.

\section{KEY WORDS}

AIDS- Acquired Immunodeficiency Syndrome, HIV- Human Immunodeficiency Virus, CD- Cluster of Differentiation.

HOW TO CITE THIS ARTICLE: Gupta HR, Yadav B, Kichu U, et al. Study of haematological abnormalities in HIV patients and correlation with bone marrow changes at a tertiary care centre. J. Evolution Med. Dent. Sci. 2018;7(36):4045-4050, DOI: $10.14260 /$ jemds/2018/903

\section{BACKGROUND}

Clinically significant haematologic abnormalities are common in people affected with HIV infection. Multiple mechanisms have been described as impaired haematopoiesis immunemediated cytopenias and altered coagulation mechanisms, out of which most of the abnormalities are caused by HIV infection, sequelae of HIV related opportunistic infection or malignancy.

'Financial or Other Competing Interest': None.

Submission 13-06-2018, Peer Review 22-08-2018,

Acceptance 27-08-2018, Published 03-09-2018.

Corresponding Author:

Dr. Hemant R. Gupta,

\#203, Erica Dosti Acres Complex,

Near Antophil Bus Depot Wadal (E),

Antophil Mumbai-400037,

Maharashtra, India.

E-mail:dr.hemantgupta@hotmail.com

DOI: $10.14260 /$ jemds $/ 2018 / 903$

\section{(c) $($ ) $(-)$}

Some of the Mechanisms that may be Operative are-

1. A direct suppressive effect of HIV on haematopoietic progenitors or marrow stromal cells, autoimmune process.

2. Infiltration of the bone marrow.

3. Ineffective erythropoiesis.

4. Nutritional deficiencies.

5. Suppression of erythropoietin.

6. Cytokine-mediated suppression.

7. Drug toxicity.

In general, haematological abnormalities progress in frequency and severity with progression of infection from asymptomatic HIV carrier state to later asymptomatic stages of the disease.(4) 


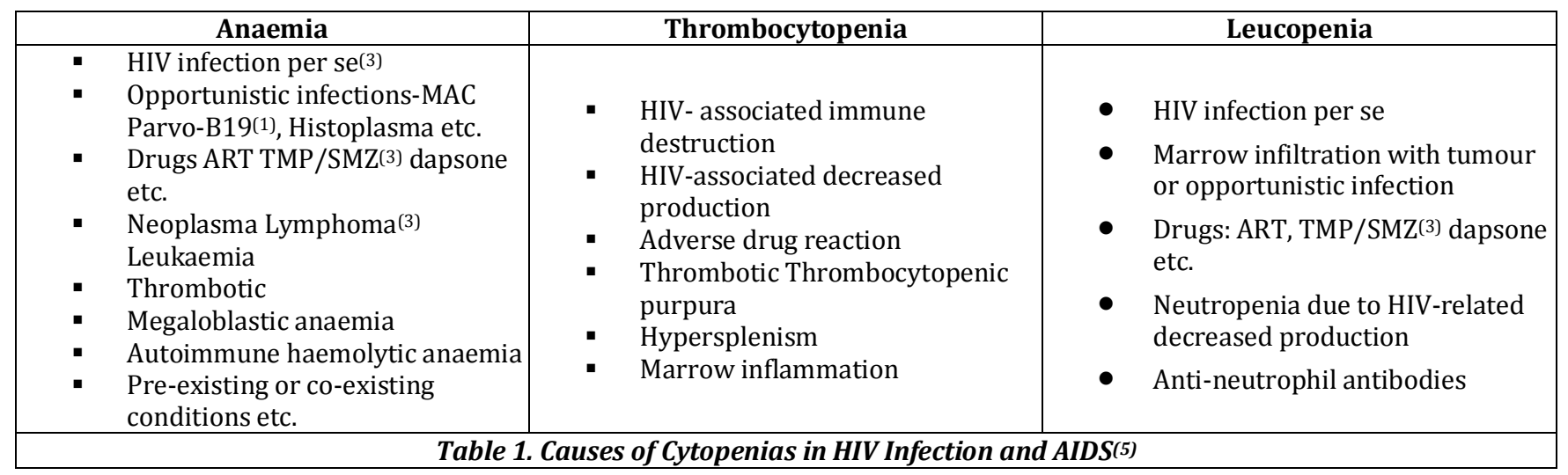

Morphologic and Histologic Abnormalities of Peripheral Blood and Bone Marrow in Patients with HIV InfectionPeripheral Blood

1. Red Cells

- Normochromic normocytic anaemia.

- Anisocytosis and poikilocytosis(6)

- Rouleaux

- Schistocytes

- Reticulocytopenia

- Basophilic stippling

- Macrocytosis (During Zidovudine Therapy)

2. Neutrophils

- Enlarged

- $\quad$ Shift to left

- Hyposegmented with Pelger-Huet forms(7)

3. Other

- Plasmacytoid lymphocytes.

- $\quad$ Large vacuolated monocytes.

4. Bone marrow changes.

5. Marrow hypercellularity.

6. Dyserythropoiesis.

7. Erythroid hypoplasia.

\section{Objectives}

1. To review and describe bone marrow abnormalities and associated peripheral abnormalities in HIV/ AIDS patients.

2. To establish the prevalence of trilineage cytopenia.

3. To determine presence of secondary malignancies.

\section{MATERIALS AND METHODS}

\section{Study Design}

A prospective descriptive clinical study with 104 HIV-positive patients consisting of 39 AIDS patients and 65 non-AIDS patients were undertaken to study of haematological abnormality in HIV patients and correlation with bone marrow changes at tertiary care centre.*

\section{Source of Data}

Patients detected to be HIV positive as per WHO criteria attending the Department of Medicine, at Tertiary Care Centre with peripheral haematological abnormalities on complete haemogram.

\section{Inclusion Criteria}

Patients tested positive for HIV as per NACO guidelines (age above 12 yrs.) and having anyone on the following haematological abnormalities on peripheral smear-

- Anaemia $(\mathrm{Hb}<10.0 \mathrm{~g} \%)$

- Leucopenia (Total Leukocyte Count $<4,000$ cells/uL)

- Thrombocytopenia (Platelet count $<1$ lakh $/ \mathrm{mm}^{3}$ )

- Pancytopenia

- Patients given written informed and valid consent.

\section{Exclusion Criteria}

Patients with any of the following-

- Patients of malignancy not related to HIV diseases.

- Patients receiving chemotherapy or radiotherapy.

- Patients of Hepatitis B and Hepatitis C viral infections.

- Chronic liver diseases (other than explained by HIV).

- Renal diseases (other than explained by HIV).

- Patients on anti-retroviral therapy.

\section{Method of Collection of Data}

- After pre-test counselling, blood samples were tested for anti-HIV antibodies by ELISA screening test.

- A detailed clinical history and examination was done and information related to each patient was filled in proforma. Complete haemogram and $\mathrm{CD}_{4}{ }^{+}$cell counts were done in all patients. Patients were divided into 2 groups based on their $\mathrm{CD}_{4}+$ counts as AIDS $\left(\mathrm{CD}_{4}+\right.$ $<200 / \mathrm{uL})$ and non-AIDS $\left(\mathrm{CD}_{4}{ }^{+}>200 / \mathrm{uL}\right)$.

- After taking written informed consent from patients eligible for this study, a bone marrow aspiration and biopsy from posterior-superior iliac spine was done under aseptic precautions using Salah needle and Jamshidi needle (11 or 13 gauge size) for aspiration and biopsy respectively. Peripheral smear and bone marrow examination findings were correlated with $\mathrm{CD}_{4}{ }^{+}$count.

\section{Statistical Methods}

Descriptive statistical analysis has been carried out in the present study. Results on continuous measurement are presented on mean SD (Min-Max) and results on categorical measurements are presented in number (\%). Significance is assessed at $5 \%$ level of significance.

Chi-square/ Fisher's exact test has been used to find the significance of study parameters on categorical scale between two or more groups. 95\% Confidence Interval has been computed to find the significant features. Confidence Interval with lower limit more than $50 \%$ is associated with statistical significance. The Statistical Software namely SPSS 16.0 Stata 
8.0 were used for the analysis of the data and Microsoft Word and excel have been used to generate graphs, tables etc.

\section{RESULTS}

Baseline haematological parameters.

\begin{tabular}{|c|c|c|}
\hline HB & Frequency & Percent \\
\hline$<6$ & 41 & 39.42 \\
\hline 6 to 9 & 42 & 40.38 \\
\hline 9 to 13 & 21 & 20.19 \\
\hline Total & $\mathbf{1 0 4}$ & $\mathbf{1 0 0}$ \\
\hline
\end{tabular}

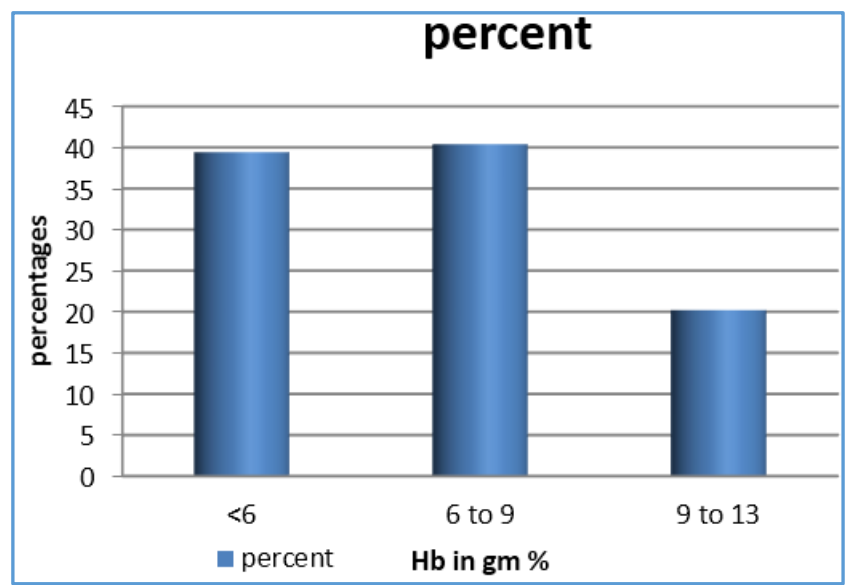

Out of 104 patients in 42 patients, $\mathrm{Hb} \%$ was between 6 and 9 gms $\%, 41$ patients $\mathrm{Hb} \%$ was $<6 \mathrm{gms} \%$ and 21 out of 104 patients were having $\mathrm{Hb} \% 9$ to $13 \mathrm{gm} \%$.

Figure 1. Distribution of Haemoglobin

\begin{tabular}{|c|c|c|}
\hline Platelets & Frequency & Percent \\
\hline$<1.5$ & 21 & 20.19 \\
\hline $1.5-4$ & 82 & 78.85 \\
\hline$>4$ & 1 & 0.96 \\
\hline Total & $\mathbf{1 0 4}$ & $\mathbf{1 0 0 . 0 0}$ \\
\hline
\end{tabular}

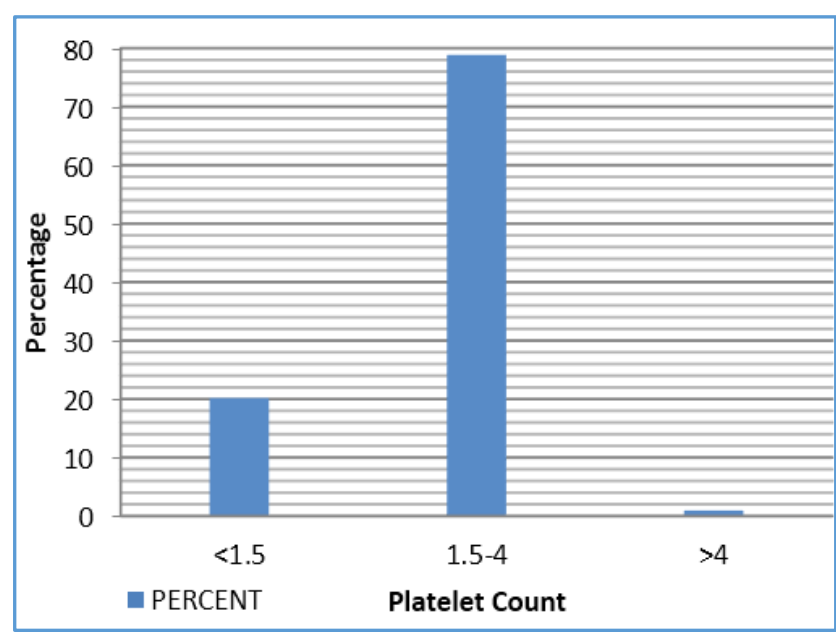

Figure 2. Distribution of Platelets

The platelets count ranges from 0.3 to 4.2 lakhs/cmm3 with prevalence of thrombocytopenia of about $20 \%$.

\begin{tabular}{|c|c|c|}
\hline Total Leucocyte Count & Frequency & Percent \\
\hline$<4000$ & 46 & 44.23 \\
\hline $4000-11000$ & 41 & 39.42 \\
\hline$>11000$ & 17 & 16.35 \\
\hline Total & $\mathbf{1 0 4}$ & $\mathbf{1 0 0 . 0 0}$ \\
\hline \multicolumn{2}{|r|}{ Table 4. Distribution of Total Leucocyte Count } \\
\hline
\end{tabular}




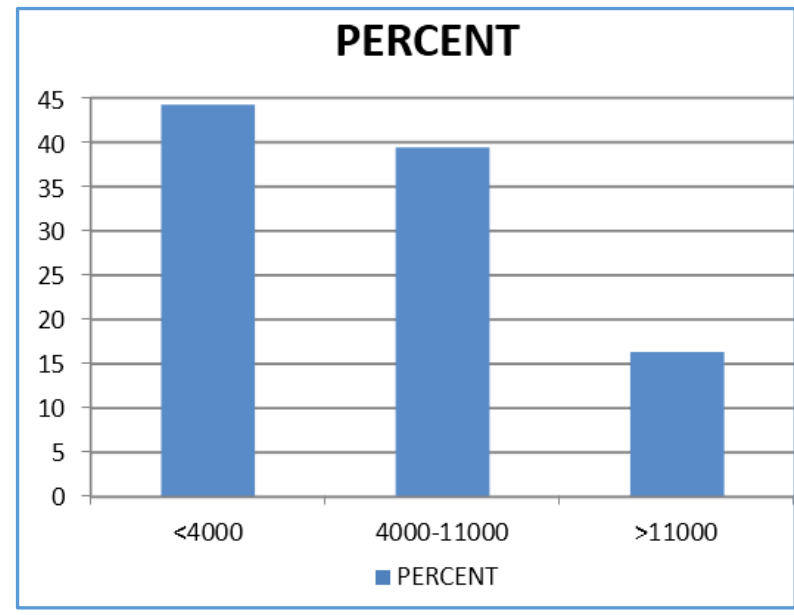

\section{Total Leucocyte Count}

The total leucocyte count ranged from 800 cells $/ \mathrm{mm} 3$ to 19,000 cells $/ \mathrm{mm} 3$ with out of 104 patients. The total leucocyte count between 4000 to 11,000 for 41 (39.42\%) patients $<4000$ for $46(44.23 \%)$ patients and $>11,000$ for 17 $(16.35 \%)$ patients.

Figure 3. Distribution of Total Leucocyte Count

\begin{tabular}{|c|c|c|c|c|c|c|}
\hline \multirow[t]{2}{*}{ Bone Marrow Cellularity } & \multicolumn{2}{|c|}{ AIDS 39} & \multicolumn{2}{|c|}{ Non-AIDS 65} & \multirow[t]{2}{*}{ Total } & \multirow[t]{2}{*}{ P value } \\
\hline & Count & $\%$ & Count & $\%$ & & \\
\hline Normocellular & 21 & 53.85 & 37 & 56.92 & 0.0011 & \\
\hline Hypocellular & 12 & 30.77 & 4 & 6.15 & & \\
\hline Hypercellular & 6 & 15.38 & 24 & 36.92 & & \\
\hline Total & 39 & 100.00 & 65 & 100.00 & & \\
\hline
\end{tabular}

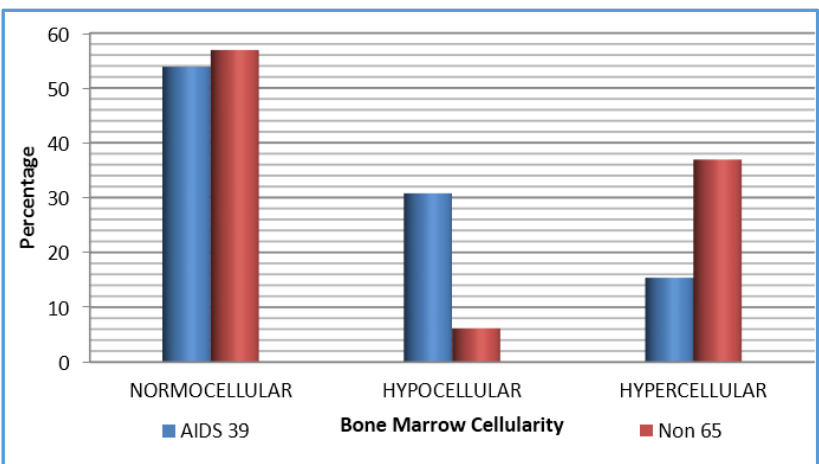

Figure 4. Distribution of Bone Marrow Cellularity in AIDS and Non-AIDS Patients
Amongst non-AIDS patients, normocellularity was the most common bone marrow picture seen in 37 out of 65 (56.92\%) patients followed by hypercellularity and hypocellularity that were seen in 24 out of 65 (36.92\%) and 4 out of $65(6.15 \%)$ patients respectively. Even among AIDS patients, normocellularity was the most common bone marrow picture seen in 21 out of 39 (53.85\%) patients followed by hypocellularity and hypercellularity that were seen in 12 out of $39(30.77 \%)$ and 6 out of 39 (15.38\%) patients.

\begin{tabular}{|c|c|c|c|}
\hline \multirow{2}{*}{$\begin{array}{c}\text { Erythroid Dysplasia } \\
(\mathbf{n = 1 6 )}\end{array}$} & Megaloblastic & Basophilic Stippling & Total \\
\cline { 2 - 4 } & $12(75 \%)$ & $4(25 \%)$ & $16(100 \%)$ \\
\hline \multirow{2}{*}{ Granulocytic dysplasia (n=6) } & Cytoplasmic Vacuolation & Nuclear Dysmorphism & Total \\
\cline { 2 - 4 } Megakaryocytic dysplasia (n= 2) & $4(66.66)$ & $2(33.33)$ & Total \\
\hline \multicolumn{2}{|c|}{ Hypolobulation } \\
\hline \multicolumn{2}{|c|}{$2(100 \%)$} & $2(100 \%)$ \\
\hline
\end{tabular}

Dysplastic changes in Erythroid series amongst a total of 16 patients were megaloblastoid changes in $75 \%(n=12)$ and Basophilic stippling in $25 \%(n=4)$ and almost all patients in this $87.5 \%(n=14)$ were in Stage III and Stage IV. Amongst the patients with dysplastic changes in Granulocytic series $(n=6)$, Cytoplasmic vacuolation was seen in $66.6 \%(n=4)$ and nuclear dysmorphism in 33.3\% ( $\mathrm{n}=2)$. All patients with granulocytic dysplasia were in Stage III and Stage IV. There were only two patients with dysplastic changes in Megakaryocytic series $(n=2)$, who had Hypolobulation and was in stage II.

\begin{tabular}{|c|c|c|c|c|c|c|}
\hline Cytopenia & \multicolumn{2}{|c|}{ AIDS } & \multicolumn{2}{c|}{ Non-AIDS } & \multicolumn{2}{c|}{ Total } \\
\hline & Count & $\mathbf{\%}$ & Count & \% & Count & \% \\
\hline Bicytopenia (B) & 17 & 43.60 & 13 & 20.00 & 30 & 28.80 \\
\hline Pancytopenia(P) & 6 & 15.40 & 4 & 6.20 & 10 & 9.60 \\
\hline 1 cell line cytopenia (M) & 116 & 41.00 & 46 & 73.60 & 54 & 61.50 \\
\hline Total Table 7. Peripheral Haematological Abnormalities in Non-AIDS and AIDS Patients & $\mathbf{1 0 0}$ \\
\hline
\end{tabular}




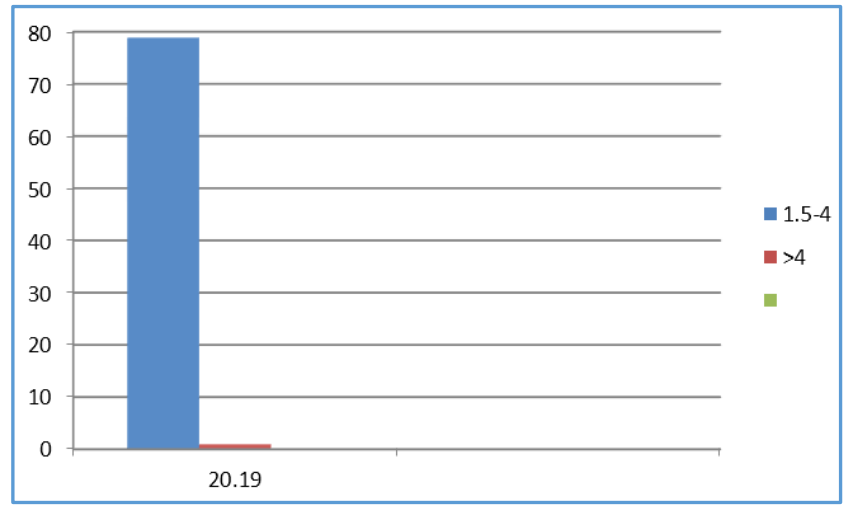

Figure 5. Peripheral Haematological Abnormalities in Non-AIDS and AIDS Patients
Bicytopenia was seen in 30 (28.80\%) out of 104 patients and it was seen in 13 (20\%) of Non-AIDS and 17 (43.60\%) of AIDS patients.

Pancytopenia was seen in $10(9.60 \%)$ out of 104 patients ant it was seen in $4(6.20 \%)$ of non-AIDS and $6(15.40 \%)$ of AIDS patients and only 1 cell line cytopenia seen in 64 $(61.50 \%)$ out of 104 patients and it was seen in $48(73.80 \%)$ of Non-AIDS and $16(41 \%)$ of AIDS patients, both pancytopenia and bicytopenia are more common in AIDS than Non-AIDS patients.

Bone marrow examination was of diagnostic usefulness in patients with fever with anaemia, thrombocytopenia or leucopenia which was frequently seen in patients infected with HIV which would be of definite use in detecting infectious pathogens and HIV-associated malignancy.

\begin{tabular}{|c|c|c|}
\hline (N= 104) & No. of Patients & \% \\
\hline AFB positive Granuloma & 04 & 3.64 \\
\hline Histoplasma-capsulatum & 01 & .96 \\
\hline Parvovirus B-19 & 02 & 1.92 \\
\hline Hodgkin's lymphoma & 01 & .96 \\
\hline Table 8. Specific findings in Bone Marrow related to Infectious Pathogen/Malignancy \\
\hline
\end{tabular}

4/104 patients, $3.84 \%$ patients showed epithelioid granulomas in bone marrow biopsies. All granuloma which were caseating epithelioid granuloma showed AFB positivity small clusters of histoplasma capsulatum along with lymphohistiocytic aggregates were seen in $1 / 104$ patients $(0.9 \%)$.

1/104 (0.9\%) patients showed Reed-Sternberg (RS) cells in bone marrow and was of mixed cellularity.

$2 / 104$ of all patients and 2/90 of anaemic patients showed presence of giant pronormoblasts with clumped basophilic chromatin and clear cytoplasmic vacuoles made on bone marrow examination was suggestive of Parvovirus B19, later the diagnosis confirmed by in situ hybridization using sequence-specific DNA probes for Parvovirus B19.

\section{DISCUSSION}

Total patients included in the study were 104, out of which males were 66 and females were 38. Majority (80\%) of the patients were in the age group of $21-40$ years. ${ }^{8}$ In the present study $62.5 \%(n=65)$ were non-AIDS patients, while the rest $33.50 \%(n=39)$ were AIDS patients. ${ }^{8}$

The most common indication for bone marrow aspiration was anaemia observed in $86.50 \%$ followed by leucopenia and thrombocytopenia, which were seen in $44.20 \%$ and $20.2 \%$ respectively. 8,9

Anaemia, leukopenia and thrombocytopenia were more common in the patients with AIDS than in those with nonAIDS patients.

Normocytic normochromic anaemia was the commonest type of anaemia seen in 58 out of 90 patients (64.40\%) followed by microcytic hypochromic anaemia seen in 26 out of 90 patients $(28.90 \%)$ and macrocytic anaemia seen in 6 out of 90 patients $(6.7 \%){ }^{8}$

Bone marrow was normocellular in $55.76 \%$ of the cases, hypercellular in 28.84 of the cases and hypocellular in $15.38 \%$ of the cases. $8,10,11$

The higher percentage of hypocellular bone marrow was observed in AIDS than in non-AIDS and was statistically significant.
Overall dysplasia was seen in $23.10 \%$ of the patients. Dysplasia was seen in $35.90 \%$ of AIDS patients as compared to only $15.4 \%$ of non-AIDS patients.

Erythroid dysplasia was the commonest dysplasia and was seen in $15.38 \%$ of all cases and $66.66 \%$ of all dysplasias. ${ }^{8}$

Lymphoid cells were decreased in $30.77 \%$ of non-AIDS and $56.41 \%$ of AIDS patients and this was statistically significant.

1 patient out of 104 patient's bone marrow showed Hodgkin's lymphoma.

\section{CONCLUSION}

- Peripheral and bone marrow abnormalities are common in HIV-related disease and have significant impact on clinical outcomes and quality of life (QOL).

- The variation in the prevalence of haematological abnormalities in different stages of disease are due to number of factors which includes CD4 count, clinical disease status, drug therapy and opportunistic infections.

- At present HIV infection is more prevalent.

a. In males as compared to females.

b. In the sexually active age group of 20 - 49 years.

- Most common presenting symptom are easy fatigability, weight loss and fever.

- Most common clinical signs are pallor and oral thrush.

- The incidences of Anaemia, Leukopenia and Thrombocytopenia are more in AIDS than in Non-AIDS.

- Normocytic normochromic anaemia is the most common peripheral haematological abnormality.

- Bone marrow was normocellular on majority of the patients.

- Hypocellular bone marrow is five times more common in AIDS than in Non-AIDS.

- Dysplasia is common in AIDS than in Non-AIDS.

- $\quad$ Erythroid dysplasia is the commonest type of dysplasia.

- Patients with AIDS have higher incidence of decreased bone marrow lymphoid cell count than Non-AIDS patients. 


\section{REFERENCES}

[1] UNAIDS Beginning of the end of the AIDS epidemic gap report 17. http://www.unaids.org/sites/default/files/en/media /unaids/contentassets/documents/unaidspublication /2014/UNAIDS_Gap_report_en.pdf

[2] HIV \& AIDS in India| AVERT [cited 2014 Dec 1] http://www.avert.org/hiv-aids-india.htm

[3] Fausi AS, Lane HC. Human Immunodeficiency Virus disease: AIDS and related disorders. In: Harrison's principles of internal medicine. $18^{\text {th }}$ edn. USA: McGraw-Hill Companies, 2012: p. 1506.

[4] NACO Dept. of AIDS control National AIDS control organization Annual report 2010-11.

[5] Fauci AS, Lane HC. Human Immunodeficiency Virus disease: AIDS and related disorders. In: Harrison's principles of internal medicine. 17th edn. USA: Mc Graw-Hill Companies, 2008: p. 1179.

[6] Franchini G, Bosch ML. Genetic relatedness of the human immunodeficiency viruses type 1 and 2 (HIV-1, HIV-2) and the simian immunodeficiency virus (SIV). Ann NY Acad Sci 1989;554:81-7.
[7] Hue T, Cheyneir R, Meyerhans A, et al. Genetic organization of a chimpanzee lentivirus related to HIV1. Nature 1990;345(6273):356-9.

[8] Centers for Disease Control. Anonymous survey for simian immunodeficiency virus (SIV) seropositivity in SIV laboratory researchers. United States. MMWR Morb Mortal Wkly Rep 1992;41:814-5.

[9] Zhu T, Korber BT, Nahmias AJ, et al. An African HIV-1 sequence from 1959 and implications for the origin of the epidemic. Nature 1998;391(6667):594-7.

[10] Gottlieb MS, Schroff $R$ Schanker HM, et al. Pneumocystis carinii pneumonia and mucosal candidiasis in homosexual men: evidence of a new acquired cellular immunodeficiency. $\mathrm{N}$ Engl J Med 1981;305(24):1425-31.

[11] Friedman-Kien AE. Disseminated Kaposi's sarcoma syndrome in young homosexual men. J Am Acad Dermatol 1981;5(4):468-71. 